\title{
Digestion and absorption of polyunsaturated fatty acids
}

\author{
H Carlier, A Bernard, C Caselli
}

\author{
Département de Nutrition, ENS.BANA, Campus Montmuzard, Université de Bourgogne, \\ F21000, Dijon, France
}

(Received 20 November 1990; accepted 24 April 1991)

Text presented at the Seminar on Ingestion, Digestion, Absorption and Food Science, 11-13 September 1990, held under the auspices of the Association Française de Nutrition

\begin{abstract}
Summary - Polyunsaturated fatty acids play an important part in the structure and function of cellular membranes and are precursors of lipid mediators which play a key role in cardiovascular and inflammatory diseases. Dietary sources of essential fatty acids are vegetable oils for either linoleic or $\alpha$-linolenic acids, and sea fish oils for eicosapentaenoic and docosahexaenoic acids. Because of the specificity of the pancreatic lipid hydrolases, triglyceride fatty acid distribution is an essential parameter in the digestibility of fats. The efficiency of the intestinal uptake depends on the hydrolysis and especially on their micellarization. n-3 polyunsaturated fatty acid ethyl ester digestion is recognized to be impaired, but n-3 polyunsaturated fatty acid triglyceride hydrolysis remains a controversial point, and to some authors explains differences observed between vegetable and fish oil absorption. So additional studies are required to investigate this intestinal step. In enterocytes, morphological and biochemical absorption processes involve reesterification of long-chain fatty acids and lipoprotein formation. At this level, specific affinity of $\mathrm{I}$ - and L- FABPc (cytosolic fatty acid binding proteins) to polyunsaturated fatty acids requires further investigation. $A$ better understanding of the role of these FABPC might bring to light the esterification step, particularly the integration of polyunsaturated fatty acids into phospholipids. With reference to differences published between fish and vegetable oil absorption, longer-term absorption studies appear essential to some authors. Polyunsaturated fatty acid absorption is thought to be not very dissimilar to that of long-chain mono-unsaturated fatty acid absorption. However, several digestion and absorption specific steps are worth studying with reference to the crucial role of polyunsaturated fatty acids in the organism, and for example adaptation of possible dietary supplements.
\end{abstract}

polyunsaturated fatty acid / digestion / absorption pathway / enterocyte esterification / intestinal lipoprotein

Résumé - Digestion et absorption intestinales des acides gras polyinsaturés. Les acides gras polyinsaturés interviennent dans la structure et la fonction des membranes cellulaires et ils participent à la synthèse des médiateurs cellulaires lipidiques dont le rôle est primordial dans la prévention des maladies cardiovasculaires et la défense de l'organisme. Les sources d'acides gras indispensables, linoléique et $\alpha$-linolénique sont essentiellement d'origine végétale, alors que les acides gras essentiels, eicosapentaénoïque et docosahexaénö̈que, proviennent d'animaux marins. La distribution des acides gras sur les 3 fonctions du glycérol des triglycérides, variable selon leur origine, est un paramètre important de la digestibilité des lipides et ultérieurement de leur absorption et de leur biodisponibilité. Si les éthyl esters des acides eicosapentaénoïque et docosahexaénoïque sont reconnus pour être difficilement hydrolysés dans la lumière intestinale, des études complémentaires s'avèrent cependant nécessaires, pour mieux définir les conditions de l'hydrolyse intestinale des tri- 
glycérides d'acides eicosapentaénoïque et docosahexaénoïque, compte tenu des résultats contradictoires obtenus concernant leur absorption. L'absorption intestinale des acides gras à longue chaine nécessite la mise en place de processus biochimiques et morphologiques pour la réestérification de ces acides gras et la formation des lipoprotéines permettant ainsi leur transport dans le milieu intérieur. II semble que les deux FABPc exprimées au niveau intestinal jouent un rôle déterminant dans les processus d'absorption étant donné leur affinité différente pour les différents types d'acides gras. L'étude de la répartition chyloportale des acides gras polyinsaturés atteste de leur absorption préférentielle par la voie lymphatique, avec selon les conditions expérimentales, des caractéristiques spécifiques par comparaison avec les modalités d'absorption des acides gras à longue chaine monoinsaturés tel l'acide oléique. Ainsi, une intégration particulière dans les phospholipides des lipoprotéines intestinales est mise en évidence. Cette estérification est influencée par la quantité d'acides gras polyinsaturés administrée et le degré d'insaturation des lipides d'accompagnement. La distribution entre les VLDL et les chylomicrons est tributaire du degré d'insaturation des acides gras administrés. Les différences observées par certains auteurs dans les modalités d'absorption des huiles de poissons par comparaison avec celles d'huiles végétales invite à réaliser des expérimentations de longue durée. Toutefois l'absorption des acides gras polyinsaturés n'apparaît pas fondamentalement différente de celle des acides gras à longue chaine, en particulier mono-insaturés, mais de nombreux points sont à approfondir, étant donné l'importance physiologique des acides gras essentiels. L'intégration des acides gras polyinsaturés, dès l'entérocyte, dans les phospholipides des lipoprotéines intestinales, revêt un intérêt nutritionnel particulier dans l'éventualité d'une supplémentation en acides gras polyinsaturés essentiels motivée par une baisse d'activité des désaturases. Par ailleurs, une meilleure connaissance des mécanismes de digestibilité, permettra de définir la forme d'administration orale adaptée aux conditions optimales de l'hydrolyse intraluminale.

acide gras polyinsaturé / digestion / voie d'absorption / estérification entérocytaire / lipoprotéine intestinale

\section{INTRODUCTION}

Polyunsaturated fatty acids play an important role in the structure of cell membranes and in the synthesis of important mediators. Cell membranes consist of a lipid bilayer composed of phospholipids and cholesterol, as well as proteins which are embedded in this lipid bilayer. Differences exist between various cell types in the incorporation and metabolization of fatty acids provided with the diet and between incorporation into specific cellular phospholipids (Galloway et al, 1985). Particularly $n-3$, polyunsaturated fatty acids have a very specific role in the membrane of the nervous system (Bourre et al, 1989). The maintenance of appropriate membrane physico-chemical properties is essential for life processes. Thus, modifications in dietary fatty acids change membrane phospholipid fatty acid composition and affect functions mediated by membrane proteins: receptors, transport pathways and enzymes (Goodnight et al, 1982; Philbrick et al, 1987). Polyunsaturated fatty acids are precursors of lipid mediators which play a key role in cardiovascular and inflammatory diseases. In recent years, evidence has been obtained showing that polyunsaturated fatty acids may be effective in prevention and therapy of cardiovascular diseases (Dyerberg et al, 1975, 1978; Bang et al, 1976; Kromann and Green, 1980; Goodnight et al, 1982). The low incidence of atherosclerosis and chronic inflammatory diseases among the Eskimos of Greenland has been related to their traditional diet rich in long-chain $n-3$ polyunsaturated fatty acids (Dyerberg et al, 1975; Bang et al, 1976). 
The 2 real main dietary essential fatty acids are linoleic acid, C18:2, n-6 and $\alpha$ linolenic acid, C18:3, n-3 because they cannot be synthesized by mammalian organisms. But mammalian organisms are generally able to convert linoleic acid (C18:2, n-6) and $\alpha$-linolenic acid (C18:3, $n-3$ ) into $n-6$ and n-3 polyunsaturated longchain fatty acids with the participation of desaturases and elongases respectively. On the one hand, arachidonic (C20:4, n-6) and on the other hand, eicosapentaenoic (C20:5, n-3) and docosahexaenoic (C22:6, $\mathrm{n}-3)$ acids are synthesized and constitute the more important physiological polyunsaturated essential fatty acids. Arachidonic and eicosapentenoic acid are precursors of eicosanoids: prostaglandins, thromboxanes and leukotrienes, the biosynthesis of which is controlled by cyclooxygenases and endoperoxidases respectively. These eicosanoids have a broad spectrum of biological activity (Goodnight et al, 1982; Samuelsson, 1983).

\section{Biological effects and nutritional essentiality of polyunsaturated fatty acids}

In response to numerous stimuli, phospholipase $A_{2}$ splits off the arachidonic acid $(\mathrm{C} 20: 4, \mathrm{n}-6)$ which is metabolized by cyclooxygenase both to thromboxane $A_{2}$, a potentiator of platelet aggregation and a vasoconstrictor, and to prostaglandin $\mathrm{I}_{2}$. Dietary eicosapentaenoic acid (C20:5, n-3), the predominant $n-3$ fatty acid in the platelet phospholipids of seafood consumers, is released froom phospholipids and can be transformed by cyclooxygenase both into prostaglandin $I_{3}$ which is as active as the vasodilatory and antiaggregatory prostaglandin $\mathrm{I}_{2}$ derived from arachidonic acid, and into a small quantity of thromboxane $\mathrm{A}_{3}$ which is almost inactive as platelet aggregator and vasoconstrictor (Fischer and
Weber, 1983). Moreover, $n-3$ and n-6 fatty acids compete for the desaturase and elongase enzymes. As a consequence, $n-3$ fatty acids inhibit the synthesis of arachidonic acid from linoleic acid and a decrease in thromboxane $A_{2}$ synthesis may result (Holman, 1964). These biochemical and physiological aspects explain some of the proposed benefits of fish oils (Dyerberg et al, 1978; Fischer and Weber, 1983) and the intense interest developed in the biological effects and nutritional essentiality of $n-6$ and particularly n-3 long chain polyunsaturated fatty acids.

According to the interaction of the $n-6$ and $n-3$ polyunsaturated fatty acids, and the importance of their respective metabolism and biological effects, recommendations for dietary fat/fatty acid intake have been proposed assuming $2600 \mathrm{kcal} / \mathrm{day}$. Total polyunsaturated fatty acids have been evaluated at $6-7 \%$ of calories with $n-6 / n-3=4 / 1$, linoleic acid, $\alpha$-linolenic acid, and eicosapentaenoic acid and docosahexaenoic acid together at 4.8-1.0 and $0.27 \%$ of calories respectively. Saturated fatty acids have been evaluated at $6-7 \%$ of calories and total mono-unsaturated fatty acids at $12-14 \%$ of calories (Lasserre et al, 1985; Simopoulos, 1989). There is a limiting step in the transformation of linoleic acid and $\alpha$-linoelic acid into derivatives. If a loss of desaturase activity prevents endogenous synthesis of arachidonic acid, or of eicosapentaenoic acid, the dietary doses of $\mathrm{C} 18$ essential fatty acids must be modulated with certain disease states and with aging (Brenner, 1981) implying a possible supply, for example, in $\gamma$-linolenic acid, C18:3, n-6.

\section{Source of polyunsaturated fatty acids and chemical characteristics (table I)}

Vegetable oils such as sunflower, soy bean, peanut, and corn oils constitute a 
substantial source of linoleic acid. Moreover, some vegetable oils such as soy bean and low erucic acid rapeseed (canbra oil in table I) oils contain both n-3 and $\mathrm{n}-6, \mathrm{C} 18$ polyunsaturated fatty acids. Evening primrose oil, blackcurrant oil, and borage oil provide significant amounts of C18:3, n-6 $\gamma$-linolenic acid and some C18:4, n-3 stearidonic acid, particularly blackcurrant oil (Lawson and Hughes, 1988c). The derived $\mathrm{C} 20$ and $\mathrm{C} 22$ essential fatty acids may be found in animals. While land animals provide arachidonic acid $(C 20: 4, n-6)$, sea animals and especially fish oils constitute some important natural sources of $n-3$ polyunsaturated fatty acids: eicosapentaenoic acid (C20:5, n3) (EPA) and docosahexaenoic acid $(\mathrm{C} 22: 6, \mathrm{n}-3)(\mathrm{DHA})$. However there is a wide variation in fatty acid composition according to the species. For example, herring and mackerel depot fats are rich in gadoleic (C20:1) and erucic (C22:1) acids (17-26\% and $11-16 \%$ respectively) and poor in eicosapentaenoic (C20:5, n-3) and docosahexaenoic (C22:6, n-3) acids (6$7 \%$ and $5-8 \%$ ). In contrast, menhaden oil contains 16 and $8 \%$ respectively of eicosapentaenoic and docosahexaenoic acids.

Triglyceride fatty acid distribution is an important parameter in the digestibility of fats (table II). Unsaturated fatty acids occupy the 2-position of glycerol in fats of most mammals, except for pigs. Gammalinolenic acid, $C 18: 3, n-6$, is found in 2and 3-positions of evening primrose, blackcurrant, and borage (Lawson and Hughes, 1988c). In the same manner, saturated fatty acids are in 1- and 3-positions and linoleic acid in the 2-position of glycerol in most plant oils. Several differences occur in the marine oil triglyceride chemical structure. For example, eicosapentaenoic acid and docosahexaenoic acid are often found in the 2-position in the glycerol of mackerel, herring, and cod oils, whereas in fat of seal and polar bear eicosapen- taenoic and docosahexaenoic acids occupy the 1- and 3-positions (Brockerhoff and Yurkowski, 1966; Brockerhoff et al, 1966a, 1968; Bottino et al, 1967). In MaxEPA, a purified fish oil preparation, eicosapentaenoic acid occupies both the 2- and 1-, 3-positions and docosahexaenoic acid preferentially the 2-position (Chernenko et al, 1989).

\section{Intestinal availability of polyunsaturated fatty acids}

The availability of these different polyunsatured fatty acids is determinant for their biological utilization. This availability is conditioned by digestion and intestinal absorption of polyunsaturated fatty acid triglycerides, since triglycerides remain the main source of dietary lipids.

The digestion and absorption of saturated and mono-unsaturated long-chain fatty acid triglycerides have been largely reviewed (Brindley, 1977; Thomson, 1978; Friedman and Nylund, 1980; Thomson and Dietschy, 1981; Tso and Simmonds, 1984; Bernard and Carlier, 1989; Thomson et al, 1989). Conversely, long-chain polyunsaturated fatty acid triglyceride digestion and absorption studies began only a few years ago (Nelson and Ackman, 1988) and sometimes gave conflicting results (McDonald et al, 1980; Chen et al, 1987b; Nilsson et al, 1987; Chernenko et al, 1989; Pavero et al, 1989). The assumption of most investigators was that polyunsaturated fatty acids are digested and absorbed through normal processes similar to those of mono-unsaturated long-chain fatty acids. However, some researchers suggested a possible substantial blood absorption pathway for polyunsaturated fatty acids with reference to their hydrosolubility properties (McDonald et al, 1980, 1987). 


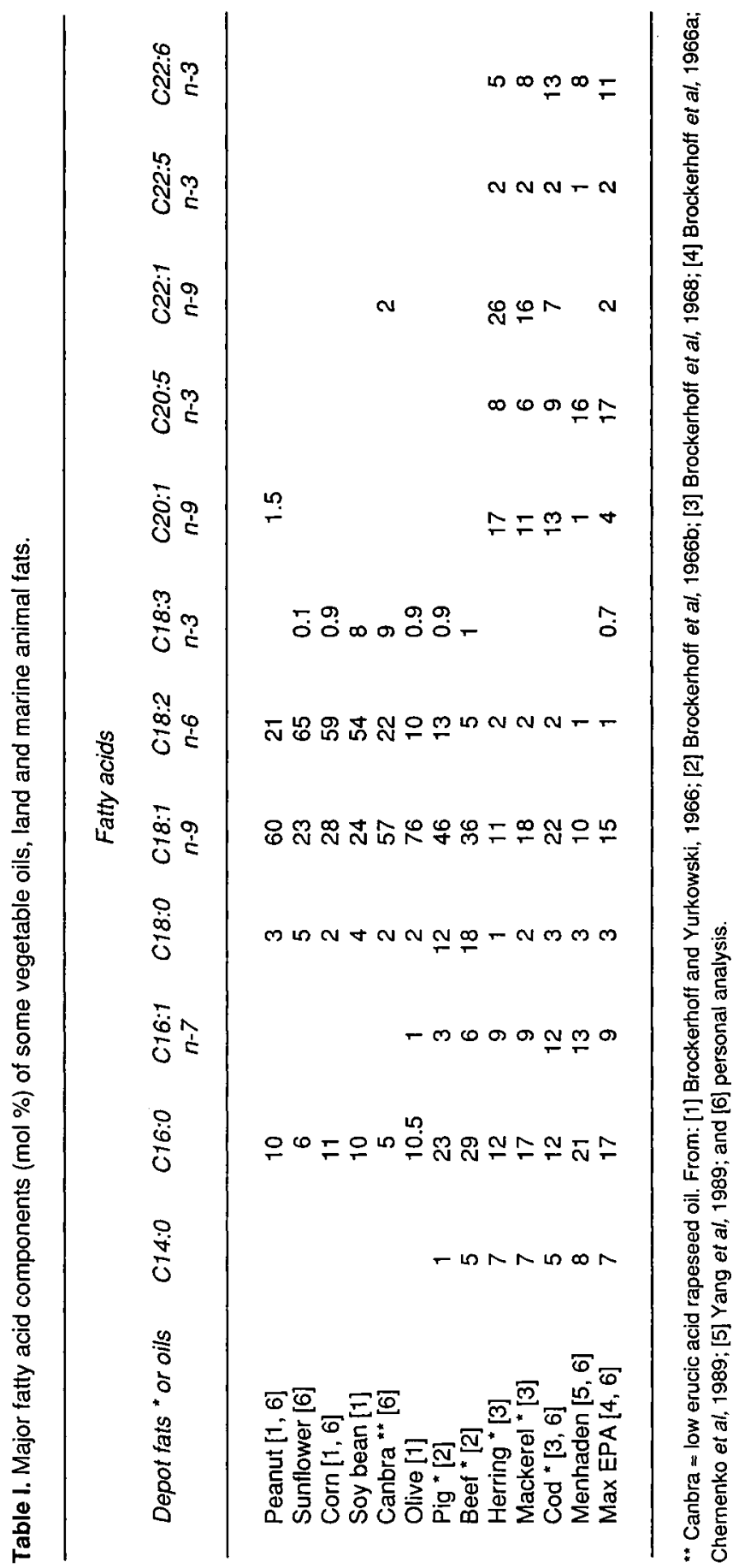




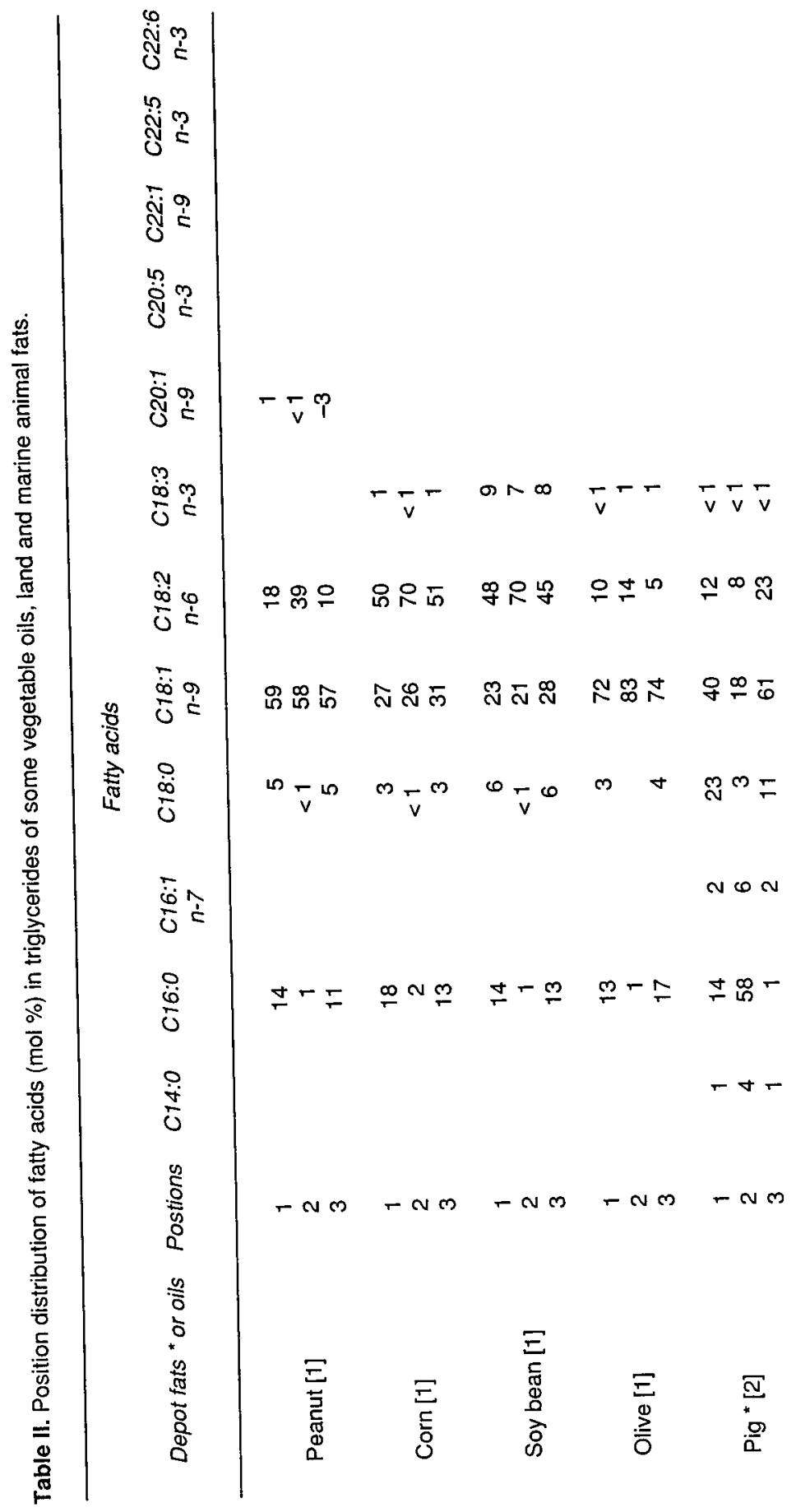




$$
\begin{aligned}
& \text { - }
\end{aligned}
$$

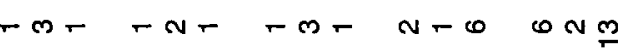

$$
\begin{aligned}
& \text { \#以 } \\
& m \underset{\sim}{\infty} \forall=\infty \quad m \mp \underset{\sim}{N} m-\infty \quad \forall-\forall \\
& \text { ผึํำ }
\end{aligned}
$$

mm- n-n n-n

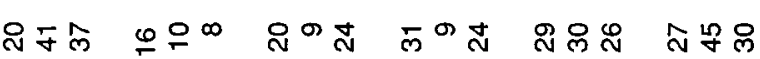

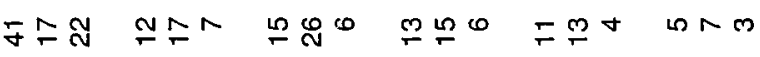

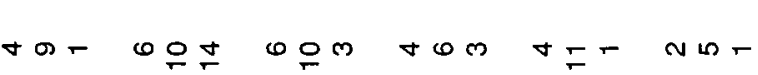

$-4 m-n m-n m-n m-n m-n b$

กod

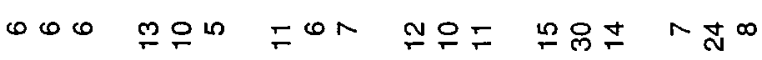


The aim of this review is to expose long-chain fatty acid triglyceride digestion and absorption processes with emphasis on polyunsaturated fatty acid absorption. Several aspects are worth studying: i), Is the gastric and intestinal hydrolysis of polyunsaturated fatty acid triglycerides, or more generally of polyunsaturated fatty acid esters, similar to that of saturated and mono-unsaturated fatty acid triglycerides? ii), Does the presence of double bonds increase mucosal catabolism of these fatty acids during their absorption? iii), What is the chyloportal partition of polyunsaturated fatty acids? iv), If the lymphatic pathway remains the preferential mode of transport of polyunsaturated fatty acids, what is the chemical form of integration of these fatty acids into intestinal lipoproteins: phospholipids or triglycerides? v), What are the intestinal lipoproteins which transfer them: very low density lipoproteins (VLDL) or chylomicrons? These last 3 points are determinant for their biological utilization either as an energy supply or as precursors of lipidic mediators.

\section{Stomach and intestinal steps of dietary lipid hydrolysis}

The digestion of lipids is based on hydrolysis of the different lipid constituents of the diet. Triglycerides are the main components $(96 \%)$ of human dietary lipids corresponding to $80-120 \mathrm{~g}$ per day; dietary phospholipids represent $2-4 \mathrm{~g}$ per day, enriched with $7-20 \mathrm{~g}$ of endogenous phospholipids from the bile and from the shed intestinal cells, and by sterols, especially cholesterol, and by fat-soluble vitamins.

In the stomach, the lingual lipase secreted by lingual glands in murine or gastric lipase in rabbit or in man (DeNigris et al, 1988; Moreau et al, 1988) starts hydrolysis of triglycerides. This hydrolysis takes place at the low $\mathrm{pH}$ of the stomach lumen in the absence of bile salts. In adults, due to the preferential cleaves of the 1- and/or 1- and 3-positions of triglycerides, lingual or gastric lipase mainly produces partial glycerides and free fatty acids. Such amphiphilic molecules help disperse the fat in the stomach and also in the proximal small intestine. This emulsification of lipids enhances further hydrolysis by pancreatic lipid hydrolases in the small intestine, since these enzyme activities depend on the emulsification of dietary fat. Thus, Roy et al (1979) demonstrated significantly improved digestion when rats deprived of salivary lipase were fed lipids microdispersed by ultrasonication. Furthermore, Liu et al (1987) showed that uptake of docosahexaenoic acid-fish oil was improved by dispersion in preterm infants known to have low levels of pancreatic lipase and bile salts. And Harris and Williams (1989), observed the very rapid and extensive absorption of emulsified fish oil in man.

In the proximal part of the small intestine, ie the end of the duodenum and the jejunum, the intestinal lumenal phase of the digestion of lipids by pancreatic lipid hydrolases takes place. In presence of bicarbonate-rich pancreatic juice and bile, triglycerides are included in the emulsion phase previously made in the stomach. Pancreatic bicarbonates increase the intestinal lumenal $\mathrm{pH}$ to a value allowing an optimal activity of pancreatic enzymes. Simultaneously under the detergent action of bile salts, the diameter of the emulsion oil droplets is decreased from 50000 down to $2000 \AA$. Intestinal lumen lipid emulsification is thought to be a limiting step for absorption of most long-chain fatty acids (Hofmann, 1976).

Pancreatic cholesterol ester hydrolase activated by bile salts completely hydrolyzes cholesteryl esters into free fatty acids and free cholesterol. Dietary phospholipids, less resistant than biliary phospholipids, are hydrolyzed by activated pancreatic 
phospholipase $A_{2}$ in the presence of trypsin, calcium ions and bile salts. They yield 1-lysophospholipids and free fatty acids. Above the critical micellar concentration of bile salts, pancreatic colipase, activated by trypsin, strongly binds to the lipase to allow the specific enzymatic action of the pancreatic lipase on triglycerides at the oil-water interface. Thus, triglycerides are cleaved into 2-monoglycerides and free fatty acids (Chapus et al, 1975; Borgström, 1977).

Due to the specificity of pancreatic lipid hydrolases, the hydrolysis products included free fatty acids, free cholesterol, 1-lysophospholipids and 2-monoglycerides. Free fatty acids and 2-monoglycerides are the major constituents of the terminal phase of dietary lipid intestinal lumen digestion.

\section{n-3, polyunsaturated fatty acid triglyceride digestion}

Brockerhoff et al (1966a), Yurkowski and Brockerhoff (1966) and Bottino et al (1967) reported that marine oil has an unusual fatty acid distribution pattern and observed that certain long-chain polyunsaturated fatty acids esterified in triglyceride oils of whales were resistant in vitro to porcine pancreatic lipolysis. This resistance, which seems to be independent of the position of polyunsaturated fatty acids on the glycerol molecule, was attributed to the introduction of a double bond in the $\delta-2$ through $\delta-5$ position of the fatty acid chain. It is a controversial point in vitro in the rat, when lipase and colipase were in sufficient excess over the dietary load, MaxEPA fish oil triglycerides were totally hydrolyzed into monoglycerides and free fatty acids (Chernenko et al, 1989). However, Harris and Connor (1980), reported the decrease of postprandial hypertriglyceridemia in humans fed a fatty meal, where the source of fat was sal- mon oil. Vahouny (1985) and Chen et al (1987a) demonstrated in rats that the total fatty acids recovered in lymph after respective salmon oil or menhaden oil and fish oil concentrate feeding were significantly lower than levels found after corn oil feeding. Lawson and Hughes (1988a) showed that in man, eicosapentaenoic and docosahexaenoic acids from fish oil free fatty acids were found to be completely absorbed, but only two-thirds of eicosapentaenoic and docosahexaenoic acids from the fish oil triglycerides were found to be absorbed. They observed that absorption of docosahexaenoic acid but not of eicosapentaenoic acid from fish oil triglycerides was significantly improved, from 68 to $90 \%$, by coingestion with a high-fat meal. This improvement was attributed to an enhanced pancreatic lipase activity. In vivo, in the rat, Yang et al (1989) observed that hydrolysis of menhaden oil resulted in a preferential retention of a high proportion of the polyunsaturated long chain fatty acids in the sn-2 monoglycerides and in the residual triglycerides; in contrast, the digestion of rapeseed oil led to a preferential release of free long-chain mono-unsaturated fatty acids. They concluded that the differential lumenal release of long-chain and polyunsaturated fatty acids from fish and rapeseed oils is largely due to their characteristic distribution between the primary and secondary positions in the glycerol molecule and to a much lesser extent to a chain length discrimination by pancreatic lipase. Additional studies are required to investigate intestinal modalities of polyunsaturated fatty acid triglyceride hydrolysis, especially $\mathrm{C} 20$, and C22, n-3 polyunsaturated fatty acid triglycerides.

\section{n-3, polyunsaturated fatty acid ethyl ester digestion}

Despite the fact that ethyl ester forms of fatty acids are not natural components of 
the human diet, enriched preparations of eicosapentaenoic and docosahexaenoic acids of fish oils in the form of ethyl esters have been proposed as dietary supplements. Opinions differ about fish oil C2O and $\mathrm{C} 22, \mathrm{n}-3$ polyunsaturated fatty acid triglyceride hydrolysis compared to vegetable oil, C18:1, n-9 and C18:2, n-6 unsaturated fatty acid triglyceride hydrolysis. The poor intestinal absorption of ethyl esters of $\mathrm{C} 20$ and $\mathrm{C} 22, \mathrm{n}-3$ polyunsaturated fatty acids compared to free fatty acid absorption of eicosapentaenoic and docosahexaenoic acids, is unanimously attributed to their impaired intestinal hydrolysis (Hamazaki et al, 1982; El Boustani et al, 1987; Lawson and Hughes, 1988a, b). It is now demonstrated that intestinal absorption of eicosapentaenoic and docosahexaenoic acids administered as ethyl esters takes place after their intestinal hydrolysis. Indeed, no eicosapentaenoic or docosahexaenoic ethyl esters were found either in 4h lymph samples collected from rats receiving ethyl ester, or in blood of man or rats after ethyl ester administration (Hamazaki et al, 1982, 1987; Terano et al, 1983; Reicks et al, 1990). In man, Lawson and Hughes (1988a), noted that the ethyl esters of eicosapentaenoic and docosahexaenoic acids were absorbed in a range of $20 \%$ as well as the free fatty acids. Furthermore, they showed (Lawson and Hughes, 1988b), that absorption of both eicosapentaenoic acid and docosahexaenoic acid, from fish oil ethyl esters was increased 3 -fold to $\approx 60 \%$ by co-ingestion with a high-fat meal, indicating that absorption of polyunsaturated fatty acid ethyl esters is highly dependent on the amount of co-ingested fat. In vivo in the rat, Yang et al (1989), showed that the methyl and ethyl esters are hydrolyzed $\approx 4$ times more slowly than the corresponding triglycerides, which is sufficient to maintain a saturated micellar solution of fatty acids in the intestinal lumen during digestion.

\section{Diffusion across}

\section{the unstirred water layer}

of intestinal hydrolysis products (fig 1)

As intestinal hydrolysis progresses, the hydrolysis products can move from the oilwater interface into the aqueous phase of the lumenal content allowing pancreatic lipid hydrolases to pursue their action. Particularly ionized free fatty acids which constitute more than half of the fatty acids at the $\mathrm{pH}$ of the jejunum and 2-monoglycerides enter into bile micelles, to form with phospholipids mixed micelles, multimolecular

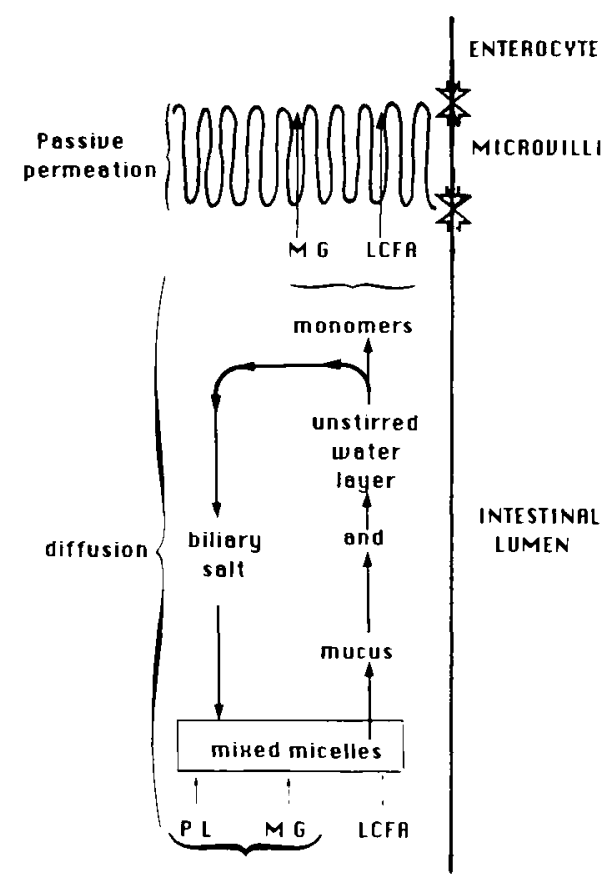

Fig 1. Micellar solubilization and passive permeation of long-chain acids. The mixed micelles diffuse towards the microvillous membrane and act as a solvent to convey apolar molecules up to the surface. The role of bile micelles is to solubilize large amounts of lipids to overcome the resistance of the unstirred water layer $(P L=$ phospholipids; $M G=$ monoglycerides; $L C F A=$ longchain fatty acids). 
aggregates of 30 to $50 \AA$. They constitute the micellar phase of lipid absorption which enables apolar lipid monomers such as saturated and mono-unsaturated longchain fatty acids to cross the unstirred water layer and mucus lining enterocyte microvillus of the intestinal villus. The transfer of the lipolysis products from the oil phase to the micellar phase appears as a critical step in the absorption of dietary fatty acids. Micellar solubilization increases uptake of lipid digestion products by increasing their aqueous concentration gradients across the unstirred water layer (Wilson et al, 1971). The partition of free fatty acids and 2-monoglycerides between the aqueous phase and the micellar phase depends on fatty acid polarity, in particular the chain length and the degree of unsaturation (Hofmann, 1976; Dietschy, 1978). The concentration of long-chain fatty acids in the water phase is low compared to that of short and medium-chain fatty acids and rises with polyunsaturated fatty acids. Mixed micelles, indispensable for the diffusion of apolar lipids across the unstirred water layer and mucus, diffuse less rapidly and release their solubilized products less readily than polar fatty acid monomers, such as short and medium-chain fatty acids and perhaps some polyunsaturated fatty acids.

\section{Uptake of long-chain fatty acids}

On the one hand the thickness of the intestinal water layer is the lowest at the distal part of the villus (Thomson and Dietschy, 1981); on the other hand, as the maturity of enterocyte increases as cells migrate from the villus crypts to the villus tips, the enzyme activity involved in the monoglyceride pathway simultaneously increases (Johnston, 1976). Thus, the site of lipid absorption is the proximal part of the small intestine, in an area corresponding to the upper third of the villus. Dissociation of mixed micelles occurs prior to lipid absorption and only monomers stemmed from the lipid lumenal hydrolysis are able to be taken up by enterocytes. This dissociation is permitted by the low $\mathrm{pH}$ microclimate which is maintained by the presence of mucus all along the lumenal side of the enterocyte microvillous membrane (Shiau et al, 1985; Shiau, 1990).

Uptake of long-chain fatty acids is believed to be an energy-independent process. This passive permeation increases with the lipophilic properties of fatty acids; consequently it increases with the chain length and decreases with the degree of unsaturation. However, at low concentration, polyunsaturated fatty acids such as linoleic and arachidonic acids may be absorbed through a facilitated diffusion mechanism without energy requirement (Chow and Hollander, 1978a,b). The role of a specific long-chain fatty acid binding protein (FABPpm) acting as a membrane receptor is not excluded (Stremmel et al, 1985). Fatty acid absorption would represent a dual, concentration-dependent uptake mechanism consisting of a passive diffusional transport process and an active carrier-mediated translocation mechanism which would be predominant at low substrate concentration as demonstrated by recent works with some long-chain fatty acids, among them linoleic and linolenic acids (Stremmel, 1988). At the cytosolic side of the enterocyte microvillous membrane, cytosolic FABPs may be responsible for the removal of long-chain fatty acids from their strong binding to the lumenal enterocyte membrane.

\section{Mucosal phase of fatty acid absorption}

The chain length of fatty acids appears to be determinant for absorption processes and particularly the absorption pathway 

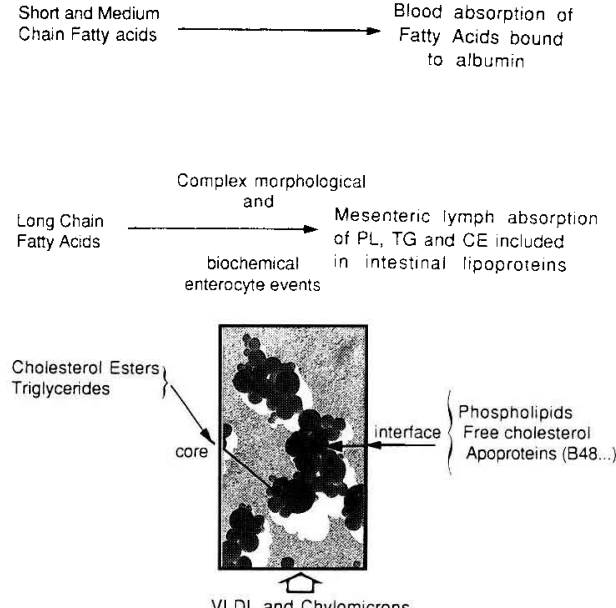

Fig 2. Chyloportal partition of fatty acids according to their chain length. Absorptive processes differ depending on the chain length of the fatty acids. On the one hand, short and mediumchain fatty acids enter the blood stream through the mesenteric portal vein bound to albumin. On the other hand, long-chain fatty acids are absorbed through lymph in esterified form included in very low density lipoproteins (VLDL) and chylomicrons.

(fig 2). Short-chain fatty acids are transported by the portal blood as free fatty acids bound to albumin, while it has been recognized for a long time that long-chain fatty acids are mainly esterified into triglycerides and delivered to the lymph included in lipoproteins: VLDL and chylomicrons (Bloom et al, 1951; Blomstrand, 1955; Borgström, 1955; Clement et al, 1963; Greenberger et al, 1966; Hyun et al, 1967; Carlier, 1971; Carlier and Bezard, 1975; Vallot et al, 1985; Bugaut and Carlier, 1987). Intestinal absorption of saturated and monounsaturated long-chain fatty acids involves correlated complex biochemical and morphological enterocyte

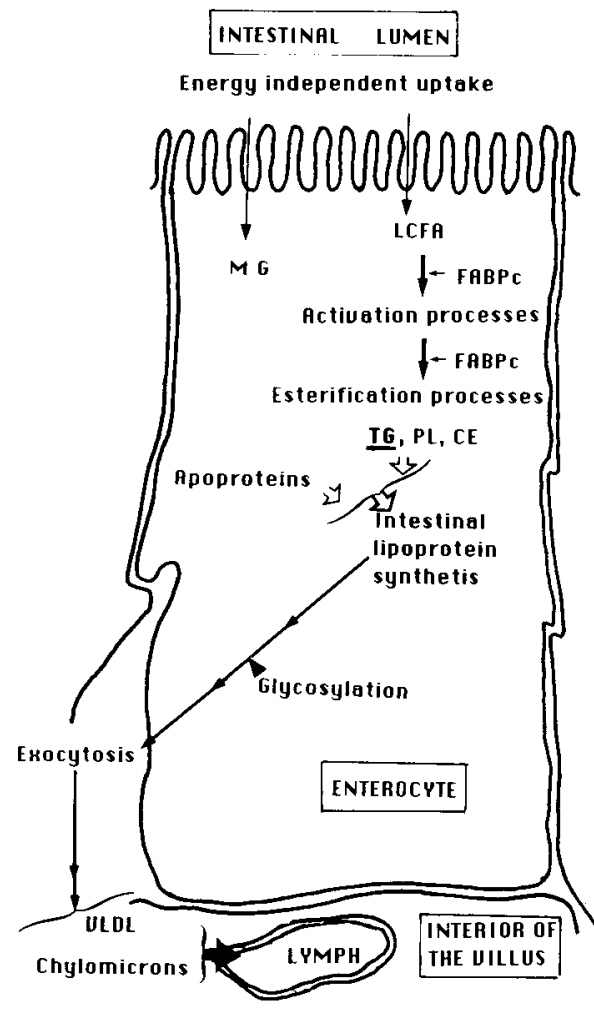

Fig 3. Long-chain fatty acid intestinal absorption steps. Cytosolic fatty acid binding proteins ( $F A B P C)$, allow the transfer of long-chain fatty acids (LCFA) towards their ultrastructural sites of activation and esterification into phospholipids (PL), cholesteryl esters (CE) and triglycerides (TG). Then association with apoproteins of reesterified long chain fatty acids give very low density lipoproteins (VLDL) and chylomicrons. After glycosylation, the newly synthesized intestinal lipoproteins are secreted in the intercellular spaces and travel towards lacteals.

events (fig 3). Intestinal lipoprotein synthesis by the masking of the hydrophobic groups of apolar long-chain fatty acids permits their transfer in the aqueous media of the lymph and then of the blood vascular compartments. 
Cytosolic fatty acid binding proteins (FABPC) bind to the apolar long-chain fatty acids and transfer them through the aqueous compartment of the enterocyte cytosol from the microvillous membrane to the endoplasmic reticulum vesicles. In 1976, Ockner and Manning attributed to the fatty acid binding protein $Z$ isolated from the intestine a higher affinity towards polyunsaturated long-chain fatty acids compared with saturated long-chain fatty acids. In fact, a few years later, 2 cytosolic fatty acid binding proteins were identified in the enterocyte: the I-FABPc (15124 Da), specific of the intestine and the L-FABPC (14273 $\mathrm{Da}$ ) expressed in the enterocyte but expressed alone in the liver (Bass, 1985). These FABPC seem to have no affinity for short- and medium-chain fatty acids. According to the work of Lowe et al (1987) I-FABPc may have an equal affinity for palmitic and arachidonic acids, whereas LFABPC may have a higher affinity only for the arachidonic acid. This point needs further investigation because of the interest in the fate of polyunsaturated fatty acids in the organism. These cytosolic fatty acid binding proteins transfer long-chain fatty acids towards their site of activation, then the activated long-chain fatty acids towards their sites of esterification in the enterocyte, that is the smooth and rough endoplasmic reticulum. The triglycerides are resynthesized mainly through the 2monoglyceride pathway (Clark and Hubscher, 1960), rather than the glycerol-3phosphate pathway (Kern and Borgström, 1965). Simultaneously with the triglyceride synthesis within the smooth endoplasmic reticulum, phospholipid and cholesteryl ester synthesis takes place within the rough endoplasmic reticulum in which an active protein synthesis is also observed, particularly the synthesis of apoprotein B48. The triglyceride synthesis through the 2monoglyceride pathway requires the presence of 2-monoglycerides as acceptors for activated fatty acids. Lumenal hydrolysis of dietary triglycerides provides enterocytes in exogenous 2-monoglycerides. They are acylated by 2 acyltransferases (a monoacylglycerolacyltransferase and a diacylglycerolacyitransferase) to 1,2-diglycerides and triglycerides respectively. These esterification processes might partly explain the impairment of the absorption of ethyl esters of eicosapentaenoic and docosahexaenoic acids administered alone, that is, without either triglycerides or monoglycerides, since an improvement in their absorption is observed when co-ingested with a high-fat meal in man (Lawson and Hughes, 1988a,b). However, in rats, Reicks et al (1990), showed that addition of olive oil to the eicosapentaenoic and docosahexaenoic ethyl ester lipid emulsion did not significantly influence lymph eicosapentaenoic and docosahexaenoic acid recoveries.

The vesiculation observed in the smooth endoplasmic reticulum and afterwards in the rough endoplasmic reticulum saccules of the supranuclear area of the enterocytes takes place simultaneously with the resynthesis of triglycerides, cholesteryl esters and phospholipids (Cardell et al, 1967; Carlier, 1971). During their transfer and progression within the rough endoplasmic reticulum, triglycerides, cholesteryl esters and phospholipids are integrated in VLDL and chylomicrons by addition of apoproteins (Bisgaier and Glikman, 1983). These newly synthesized lipoproteins are transferred towards the Golgi complex. Structural changes in the enterocytes during lipid absorption affect the Golgi apparatus, which exhibits a major enlargement of its vesicles filled with the nascent lipoproteins (Cardell et al, 1967; Carlier, 1971). This organelle appears to be an essential step for the final struturation of the intestinal lipoprotein particles, particularly their glycosylation. This packaging is necessary in order to allow the 
transport of lipoproteins within secretory vesicles towards the lateral plasma membrane and to their exocytosis from the enterocyte into the intercellular spaces, involving the participation of the microtubules for this migration (Sabesin, 1976; Bernard et al, 1979a). Intestinal lipoproteins of the intercellular spaces travel towards the basement membrane where opening gaps allow a direct communication with the lamina propria. Their transfer into the lacteals takes place mainly through gaps between adjacent endothelial cells (Cardell et al, 1967; Carlier, 1971; Sabesin, 1976; Bernard et al, 1979b). Electron microscope micrographs of rat enterocytes after administration of canbra oil ( $57 \%$ oleic acid, $22 \%$ linolenic acid, 9\% linolenic acid) (Bernard et al, 1979a,b) and electron microscope micrographs of rat intestinal lymph particles after administration of either corn oil $(30 \%$ oleic acid, $52 \%$ linoleic acid) or menhaden oil $(9 \%$ oleic acid, $16 \%$ eicosapentaenoic acid, $7 \%$ docosahexaenoic acid) or cod liver oil $(21 \%$ oleic acid, $10 \%$ eicosapentaenoic acid, 9\% docosahexaenoic acid) (Caselli et al, 1979; Rayo et al, 1990) (fig 4), seem to indicate that absorption processes of polyunsaturated fatty acids are similar to those of saturated and mono-unsaturated fatty acids.

To clarify such an assumption, we will expose the actual state of knowledge about polyunsaturated fatty acid absorption with reference to both medium-chain fatty acid and to saturated and monounsaturated long-chain fatty acid absorption.

\section{Polyunsaturated fatty acid absorption}

In rats under vascular perfusion, 24-35\% of the infused ${ }^{14} \mathrm{C}$ decanoic acid radioactivity was recovered in the mesenteric portal venous blood during the hour which followed the intraduodenal infusion of either $90 \mu \mathrm{mol}$ of an equimolar mixture of ${ }^{14} \mathrm{C}$ decanoic acid, oleic acid and monopalmitin or of ${ }^{14} \mathrm{C}$ decanoic acid alone (Vallot et al, 1985). In contrast, in the same experimental conditions, only $1.8-2.2 \%$ of infused ${ }^{14} \mathrm{C}$ linoleic acid and 2.6 to $3 \%$ of infused ${ }^{14} \mathrm{C}$ arachidonic acid were recovered in the mesenteric portal venous blood (Bernard and Carlier, 1991). As suggested by McDonald et al (1980), we observed with ${ }^{14} \mathrm{C}$ linoleic acid administered alone, for infused loads equal or inferior to $30 \mu \mathrm{mol}$, a significant increase in blood absorption as linoleic acid doses decreased, but all the values remained lower than $5 \%$ of the infused radioactivity (Bernard et al, 1991) (fig 5). In rats with fistulated main mesenteric lymphatic duct using the same labelled lipid emulsions (fig 6), ie either $90 \mu \mathrm{mol}$ of ${ }^{14} \mathrm{C}$ fatty acid alone or $90 \mu \mathrm{mol}$ of an equimolar mixture of ${ }^{14} \mathrm{C}$ fatty acid, oleic acid and monopalmitin, only $0.36-3 \%$ of the infused ${ }^{14} \mathrm{C}$ decanoic acid was recovered in the lymph instead of $32-48 \%$ of the infused ${ }^{14} \mathrm{C}$ linoleic acid (Vallot et al, 1985; Bernard et al, 1991) and of $37-43 \%$ of the infused ${ }^{14} \mathrm{C}$ arachidonic acid during the $6 \mathrm{~h}$ following duodenal lipid infusion (Pavero et al, 1989). In the lymph, we observed a slightly higher recovery of ${ }^{14} \mathrm{C}$ linoleic acid radioactivity rather than that

Fig 4. Electron micrographs of particles of rat mesenteric lymph collected at the peak of absorption, after ingestion of either $0.5 \mathrm{ml}$ or corn oil (a) or menhaden oil (b) or cod liver oil (c) (Rayo et al, 1990). Ingestion of corn oil, menhaden oil or cod oil is followed by an increase of the intestinal formation of lipoproteins (see fig 8 ). Relative proportion of chylomicrons appears to be of the same range whatever the oil ingested, indicating a similar lymph transport pathway both for fish oil triglycerides and corn oil triglycerides. Scale bar $=0.1 \mu \mathrm{m}$. 

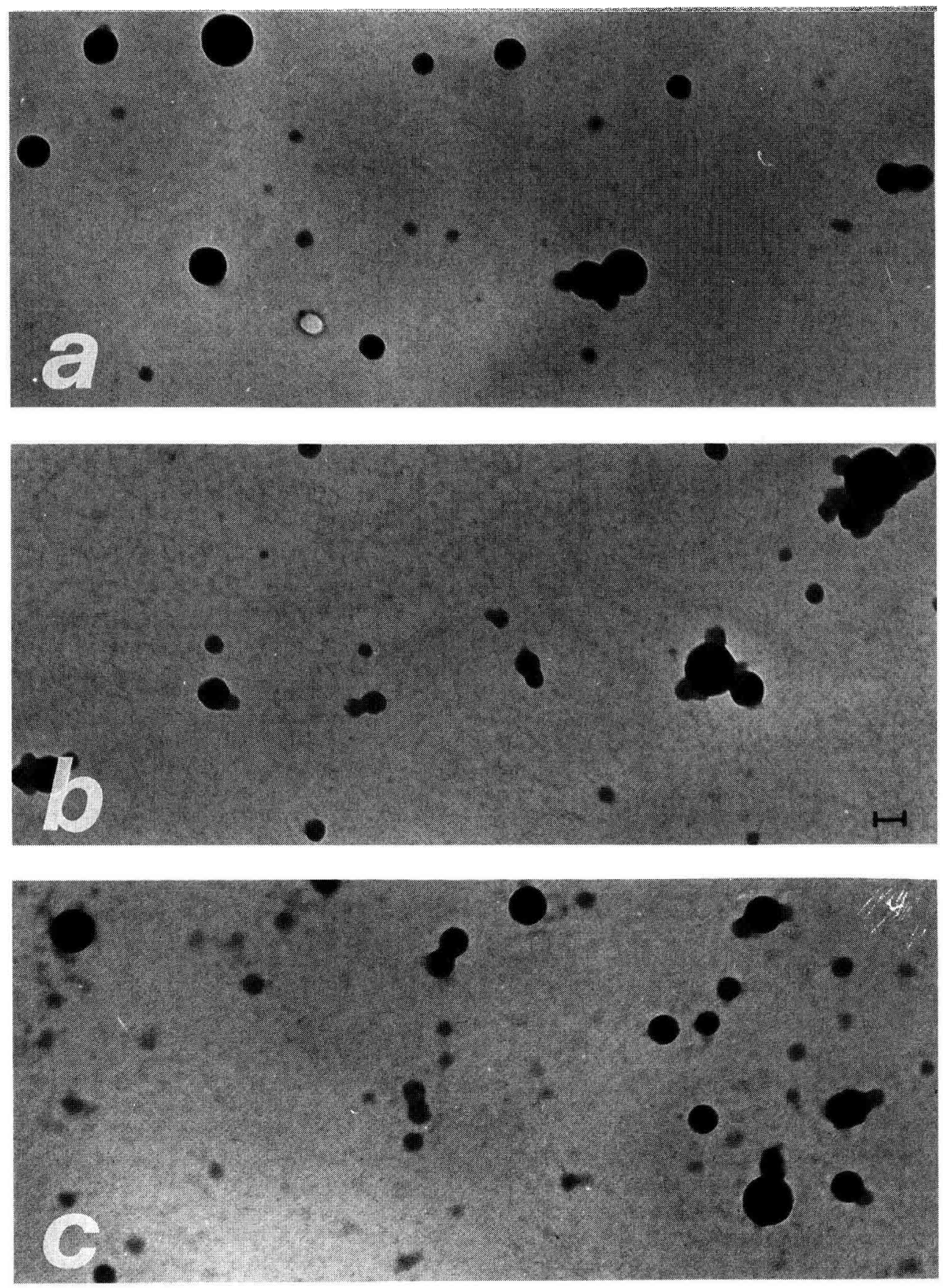

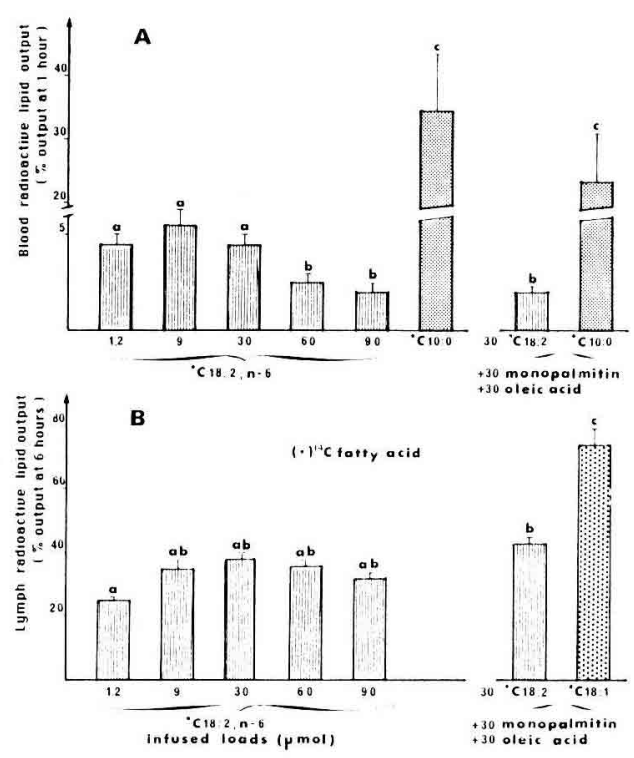

Fig 5. Blood (A) and mesenteric lymph (B) absorption of intraduodenally infused ${ }^{14} \mathrm{C}$ linoleic or ${ }^{14} \mathrm{C}$ decanoic acids either for $1 \mathrm{~h}$ in rats under vascular perfusion $(A)$ or for $6 \mathrm{~h}$ in main mesenteric lymphatic duct fistulated rats (B) (Vallot et al, 1985; Bernard et al, 1991). Values are means (SEM) for 4 rats per group. Either ${ }^{14} \mathrm{C}$ linoleic acid acid was administered alone at different loads from 1.2 to $90 \mu \mathrm{mol}$ or either $30 \mu \mathrm{mol}$ of ${ }^{14} \mathrm{C}$ linoleic acid or ${ }^{14} \mathrm{C}$ decanoic acid were infused in presence of $30 \mu \mathrm{mol}$ of oleic acid and 30 $\mu \mathrm{mol}$ of monopalmitin. Bars assigned with different letters are significantly different $(P<0.001)$. In comparison to decanoic acid and to oleic acid intestinal absorption, a preferential lymph absorption pathway occurs for linoleic acid, whatever the dose administered.

of ${ }^{14} \mathrm{C}$ arachidonic acid, as observed by Nilsson et al (1987).

Twenty-four $h$ after gastric administration of $300 \mu \mathrm{mol}$ of either oleic acid or arachidonic acid or eicosapentaenoic acid, in rats with fistulated left thoracic lymphatic channel Chen et al (1985) demonstrated

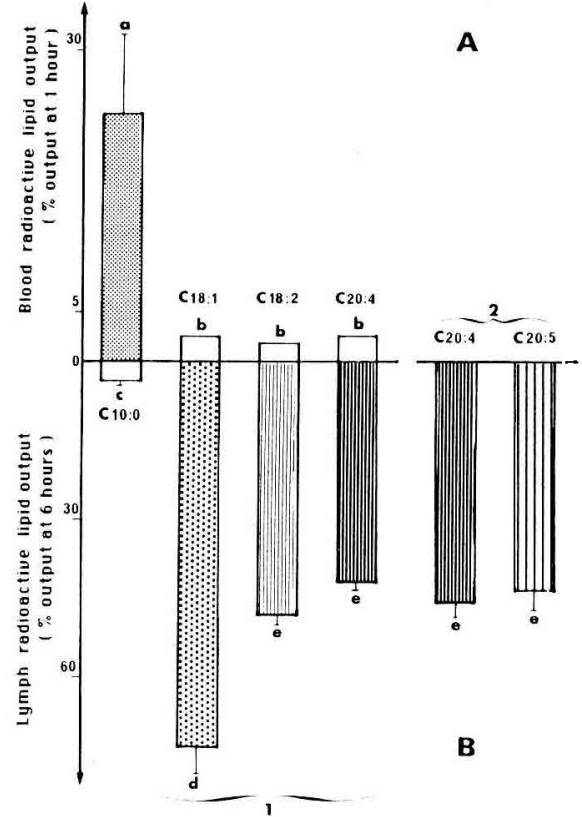

Fig 6. Blood (A) and lymphatic (B) intestinal absorption of intraduodenally infused ${ }^{14} \mathrm{C}$ fatty acids either for $1 \mathrm{~h}$ on rats under vascular perfusion (A) or for $6 \mathrm{~h}$ on main mesenteric lymph duct fistulated rats (B) (Vallot et al, 1985; Pavero et al, 1989; Bernard and Carlier, 1991; Bernard et al, 1991). Either $30 \mu \mathrm{mol}$ of ${ }^{14} \mathrm{C}$ fatty acid were administered in presence of $30 \mu \mathrm{mol}$ of oleic acid and $30 \mu \mathrm{mol}$ of monopalmitin (1), or $30 \mu \mathrm{mol}$ of eicosapentaenoic acid or docosahexaenoic acid were administered in presence of $30 \mu \mathrm{mol}$ of linoleic acid and $30 \mu \mathrm{mol}$ of monoolein (2). Values are means (SEM) for 4 to 5 rats per group. Bars assigned with different letters are significantly different $(P<0.01)$. Whatever the polyunsaturated fatty acid studied, results reveal their preferential lymph absorption pathway.

that the overall appearance of arachidonic and eicosapentaenoic acids in the lymph was quantitatively equivalent to that of oleate, although there were apparent differences in the rates of lymphatic absorption of these fatty acids. In these experiments the lymph recovery was 76.2- 
$85.6 \%$ of the quantify infused. Studies carried out on rats with fistulated main mesenteric lymphatic duct, with $90 \mu \mathrm{mol}$ of equimolar mixtures of oleic acid, monopalmitin and either ${ }^{14} \mathrm{C}$ arachidonic acids or ${ }^{14} \mathrm{C}$ eicosapentaenoic acid, gave similar recoveries of labelled lipids in lymph (45.1 and $43.7 \%$ respectively of the radioactivity infused intraduodenally $6 \mathrm{~h}$ before) (fig 6). The same similitude appeared in the results when the infusates were composed of $5 \mu \mathrm{mol}$ of either ${ }^{14} \mathrm{C}$ arachidonic acid diluted with $25 \mu \mathrm{mol}$ of linoleic acid or ${ }^{14} \mathrm{C}$ eicosapentaenoic acid diluted with $25 \mu \mathrm{mol}$ of arachidonic acid in the presence of 30 $\mu \mathrm{mol}$ of oleic acid and $30 \mu \mathrm{mol}$ of monopalmitin (Pavero et al, 1989). Whatever the experimental conditions and the dose administered, unesterified polyunsaturated fatty acids are efficiently absorbed through the lymphatic pathway, even if some differences occur in the absorption profiles, as noted by Chen et al (1985). Thus in our data, compared to oleic acid absorption, the peak of absorption was delayed by 30 min for arachidonic acid and that of linoleic acid by $60 \mathrm{~min}$, and the lymph recovery was significantly lower (Pavero et al, 1989). Such differences might be explained by the integration of these polyunsaturated fatty acids into pools of mucosal phospholipids before their effective integration in VLDL and chylomicrons.

\section{Polyunsaturated fatty acid integration in lymph phospholipids}

Most investigators noted a significant increase of labelled lymph phospholipids after labelled polyunsaturated fatty acid administration by comparison for example with a mono-unsaturated fatty acid such as oleic acid. Despite the fact that oleic, arachidonic and eicosapentaenoic acids were largely recovered in lymphatic triglycerides, particularly when administered alone (Chen et al, 1985; Nilsson et al,
1987; Pavero et al, 1989), Chen et al (1985) showed a greater incorporation of arachidonic and eicosapentaenoic acids into lymphatic phospholipids (respectively 4.5 and $4.3 \%$ of the radioactive lipids) than oleic acid $(2.1 \%)$. Can such an esterification pathway be explained, as in the liver, by a preference of 1-lysophosphatidylacylCoA transferase for unsaturated fatty acids (Nisson et al, 1987)? In vitro, with mouse jejunal explants incubated for 15 min at $37^{\circ} \mathrm{C}$ in an oxygenated culture medium enriched with lipids (1.2 mM: equimolar in monopalmitin, oleic acid and either ${ }^{14} \mathrm{C}$ oleic or ${ }^{14} \mathrm{C}$ linoleic acid) ${ }^{14} \mathrm{C}$ oleic acid was integrated mainly into triglycerides: $82.5 \mathrm{nmol}$ per $\mathrm{mg}$ of explant proteins versus $37 \mathrm{nmol} / \mathrm{mg}$ of explant proteins into phospholipids, whereas ${ }^{14} \mathrm{C}$ linoleic acid was mainly integrated into phospholipids: $74.5 \mathrm{nmol}$ per $\mathrm{mg}$ of explant proteins versus $49 \mathrm{nmol} / \mathrm{mg}$ of explant proteins into triglycerides (Bernard and Carlier, 1991; in press). This integration in lymph phospholipids is particularly enhanced in our experimental conditions in vivo in the rat, when $30 \mu \mathrm{mol}$ of monopalmitin of ${ }^{14} \mathrm{C}$ fatty acids were administered with $30 \mu \mathrm{mol}$ of oleic acid and $30 \mu \mathrm{mol}$ of monopalmitin. Thus, at the maximum of the radioactive lymph recovery (from the 30 th to the 120 th $\mathrm{min}$ after the intraduodenal infusion), 1.1 to $3.1 \%$ of the lymph lipid radioactivity was recovered in phospholipids, after ${ }^{14} \mathrm{C}$ oleic acid infusion, 7.3 to $19 \%$ of the lymph lipid radioactivity was found on phospholipids after ${ }^{14} \mathrm{C}$ arachidonic acid administration (Pavero et al, 1989) (fig 7).

The integration of polyunsaturated fatty acids into lipoprotein phospholipids appears to be influenced by the quantity of lipids infused and the degree of unsaturation of the other lipids of the lipid emulsions. Thus, in the rat, Nilsson et al (1987), observed that the incorporation of both linoleic and arachidonic acids into different lipid classes varied with the proportion of unsaturated fat in the meal: the proportion 


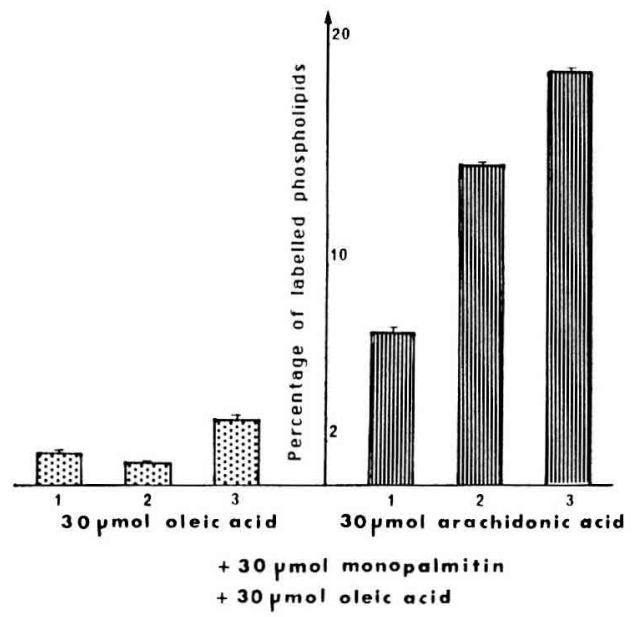

Fig 7. ${ }^{14} \mathrm{C}$ oleic and ${ }^{14} \mathrm{C}$ arachidonic acid integration into lymph phospholipids (Pavero et al, 1989). Results are percentages versus the total radioactive lymph lipids of the radioactivity recovered into lymph phospholipids. Values are means (SEM) for the second (1), the third (2) and the fourth (3) half $h$ following the intraduodenal infusion of $30 \mu \mathrm{mol}$ of either ${ }^{14} \mathrm{C}$ oleic acid or ${ }^{14} \mathrm{C}$ arachidonic acid in the presence of $30 \mu \mathrm{mol}$ of oleic acid and $30 \mu \mathrm{mol}$ of monoplamitin. A significant increase in labelled lymph phospholipids appears after labelled arachidonic acid administration compared with labelled oleic acid administration.

of the 2 polyunsaturated fatty acids in phospholipids was higher when fed in highly saturated fat ie cream instead of intralipid. Some of our results corroborated this observation: at the maximum of the radioactive lymph recovery, the integration of ${ }^{14} \mathrm{C}$ arachidonic acid into phospholipids was significantly decreased when this fatty acid was administered in the presence of linoleic acid and mono-olein rather than when ${ }^{14} \mathrm{C}$ arachidonic acid was administered with oleic acid and monopalmitin (2.8-6.5\% and $7.3-19 \%$ respectively of the lymph lipid radioactivity was recovered in the phospholipids) (Pavero et al, 1989).

\section{Marine oil absorption}

The above discussion concerns absorption studies of unesterified polyunsaturated fatty acids administered alone or with other lipids. What happens with vegetable oils rich in C18 polyunsaturated fatty acids, preferentially of the $n-6$ family, and with marine oils rich in $\mathrm{C} 20$ and $\mathrm{C} 22$ polyunsaturated fatty acids of the n- 3 family? Harris and Connor (1980) observed that the ingestion of salmon oil did not give a typical fat tolerance curve in human subjects, compared to those given a control meal containing animal and vegetable fats. These results were in agreement with $\mathrm{Va}$ houny's data in the rat (Vahouny, 1985). Then Chen et al (1987b) found that corn oil was better absorbed than menhaden oil or fish oil concentrate: $24 \mathrm{~h}$ after duodenal infusion of $170 \mathrm{mg}$ of each emulsified oil respectively $219.7-164.4$ and $152.2 \mathrm{mg}$ of fatty acids were recovered in rat thoracic lymph. In contrast, Chernenko et al (1989) did not observe any significant difference in the lymphatic absorption of $0.5 \mathrm{ml}$ of MaxEPA or olive oil given intraduodenally in a bolus to Sprague-Dawley rats, over 6 and $24 \mathrm{~h}$, over which times $\approx 40$ and $70 \%$ of the administered dose was recovered in lymph triglycerides. In the same manner Rayo et al (in press) did not observe any significant difference in lymph triglyceride output of rats fed with $0.5 \mathrm{ml}$ of either corn oil, or menhaden oil or cod liver oil, but the profiles of lymph absorption were different (fig 8). Menhaden oil was more rapidly absorbed than cod liver oil; these differences might be explained by the presence of gadoleic and erucic acids in cod liver oil. Undoubtedly, differences between authors are to be attributed to differences in experimental conditions; the role of lingual or gastric lipase must be also taken into account, as well as the fractionation delivery of the chyme from the stomach. All these 


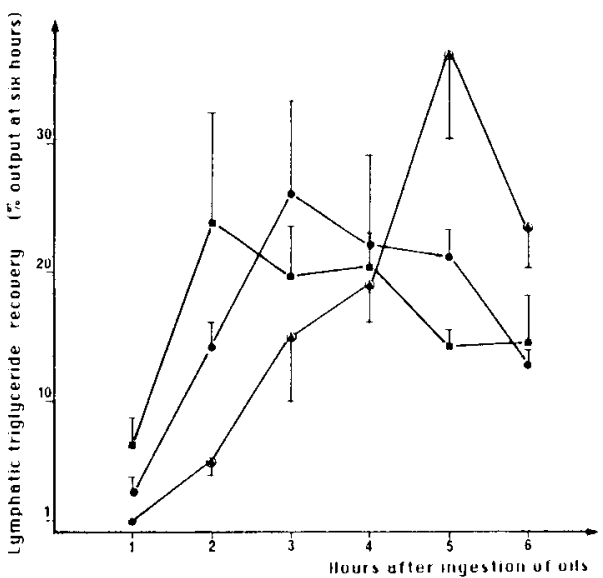

Fig 8. Lymphatic triglyceride recovery as a percentage of total lymphatic triglyceride output over 6 h (Rayo ef al, 1990). Profiles of lymphatic absorption of corn oil (O), menhaden oil (a) and cod liver oil $(\Theta)$ during the $6 \mathrm{~h}$ following the ingestion of $0.5 \mathrm{ml}$ of one of these oils in rats. Menhaden oil and corn oil are absorbed more rapidly than cod liver oil.

studies dealt with short-term absorption; longer-term animal studies appeared essential for some authors to conclude about the bioavailability of polyunsaturated fatty acids (Hamazaki et al, 1987).

\section{Polyunsaturated fatty acids and lymph lipoprotein formation}

Few works have dealt with the morphologic aspect of lymph lipoprotein particles. Chen et al (1985) subjected lymph samples to ultra-centrifugal separation and noted that the distribution of labelled oleic, arachidonic and eicosapentaenoic acids among major lymph lipoproteins were similar. The same researchers (1987a), demonstrated that the overall clearances of the EPA-enriched and oleate-enriched chylo- microns from the circulation are essentially the same. In agreement with biochemical results of Chen et al (1985), electron micrographs of lymph lipoprotein particles reveal no significant differences after administration of corn, or menhaden or cod liver oil (fig 4). In fact, percentage and size of chylomicrons appear correlated with the degree of unsaturation of the lipids administered. For example, when arachidonic acid was infused with oleic acid and monopalmitin (90 $\mu \mathrm{mol}: 30 / 30 / 30 ~ \mathrm{~mol} / \mathrm{mol} / \mathrm{mol}$ ) at peak absorption, $6.3 \%$ of the lymph lipoprotein particles were chylomicrons, while when arachidonic acid was infused with linoleic acid and mono-olein (90 $\mu \mathrm{mol}$ : 30/30/ $30 \mathrm{~mol} / \mathrm{mol} / \mathrm{mol}$ ) at peak absorption, 11.2 were chylomicrons. When arachidonic acid (5 $\mu \mathrm{mol})$ was diluted with linoleic acid (25 $\mu \mathrm{mol})$ and infused with oleic acid and monopalmitin $(30 / 30 \mathrm{~mol} / \mathrm{mol})$ at peak absorption, $7.3 \%$ of the lymph particles were chylomicrons, while, as in previous experiments, when $5 \mu \mathrm{mol}$ of arachidonic acid and $25 \mu \mathrm{mol}$ of linoleic acid were infused with linoleic acid and mono-olein (30/30 $\mathrm{mol} / \mathrm{mol}$ ), at peak absorption, $11.3 \%$ of the lymph particles were chylomicrons. In the 2 cases, the substitution of oleic acid and monopalmitin by linoleic acid and monoolein was followed by an increase in both the proportion of chylomicrons and in their size (fig 9). These observations on the influence of the unsaturation degree of fatty acids corroborate previous results obtained with vegetable oils (Caselli et al, 1979).

\section{Enterocyte metabolism of polyunsaturated long-chain fatty acids}

Chernenko et al (1989) indicated that fish oil is absorbed from the rat intestine without any major alteration in the acyl chain of the triglycerides. The results of the diges- 

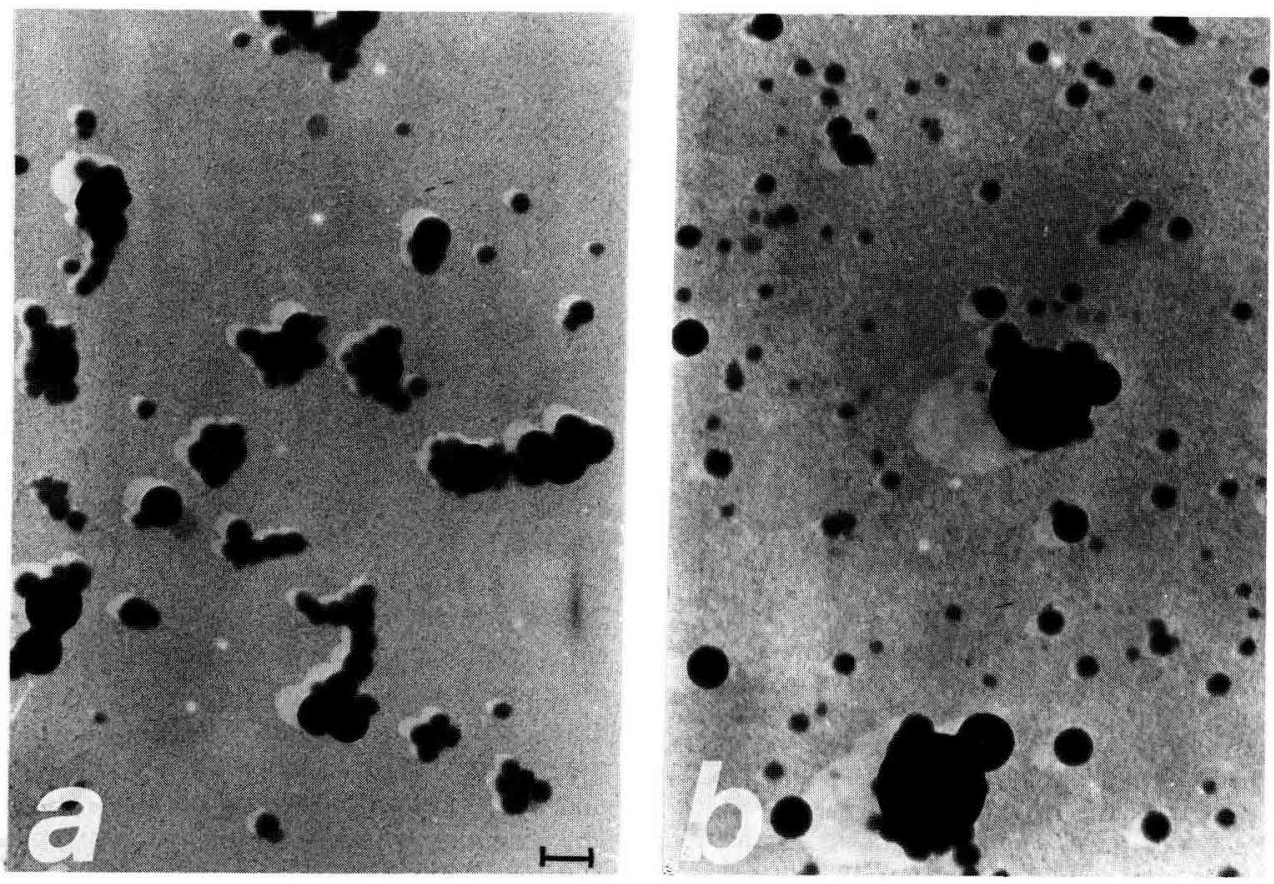

Fig 9. Electron micrographs of rat mesenteric lymph lipoprotein particles. Rat mesenteric lymph lipoprotein particles visualized at the peak of absorption of ${ }^{14} \mathrm{C}$ lipid absorption after intraduodenal infusion of $5 \mu \mathrm{mol}$ of arachidonic acid either in presence of $25 \mu \mathrm{mol}$ of linoleic acid, $30 \mu \mathrm{mol}$ of oleic acid and $30 \mu \mathrm{mol}$ of monopalmitin (a), or in presence of $55 \mu \mathrm{mol}$ of linoleic acid and $30 \mu \mathrm{mol}$ of mono-olein (b) (unpublished results). Large-size chylomicrons appear in the lymph when the degree of unsaturation of lipids administered increases. Scale bar $=0.1 \mu \mathrm{m}$.

tion of the lymph samples with lipase indicated that the positional distribution of characteristic fish oil fatty acids is similar in both the MaxEPA and the intestinal lymph. Information concerning eventual oxidation and remodeling of fatty acids in the enterocyte during their absorption is limited. Some authors have shown that endogenous plasma fatty acids were more oxidized in the enterocyte than exogenous lumenal fatty acids (Gangl and Ockner, 1975). Although the intestine was an actively metabolizing tissue, it oxidized very little of the exogenous fatty acids. the study of catabolic products recovered in mesenteric portal venous blood of rats (Bernard and Carlier, 1991) shows that the mucosal catabolism of polyunsaturated fatty acids, even higher than the mucosal catabolism of saturated and monounsaturated long-chain fatty acids, remains low compared to their absorption. In fact, this oxidation appeared in relation with the chain length, decanoic acid is significantly more oxidized than long-chain fatty acids, and with the degree of unsaturation, pal- 
mitic acid and erucic acids were significantly less oxidized than oleic, linoleic and particularly arachidonic acids (Greenberger et al, 1965; Vallot et al, 1985; Bernard and Carlier, 1991).

Christiansen et al (1986) revealed that the microsomal fraction from rat small intestine contains a fatty acid elongation activity; they showed that the activity towards saturated and mono-unsaturated fatty acids may seem similar in liver and small intestine, and that highly polyunsaturated fatty acids are markedly poorer substrates for the intestinal system. Furthermore, Garg et al (1988) showed the presence of some desaturase enzymes in the rat enterocyte. Particularly, they demonstrated that rat small intestine possesses desaturase activity to convert palmitic acid into palmitoleic acid and linoleic acid into linolenic acid. They suggested that a significant amount of arachidonic acid may originate from de novo synthesis within the enterocyte via desaturation and chain elongation of linoleic acid. In agreement with this hypothesis, labelled arachidonic acid appeared in the intestinal lymph of rats during labelled linoleic absorption, the best transformation efficiency occurring at peak absorption (Bernard et al, 1991).

A chain shortening, more or less associated to chain lengthening, of erucic acid, was described when erucic acid was administered in free form either with triglycerides (Thomassen et al, 1985), or with monoglycerides (Pavero et al, 1990).

It may be concluded that the enterocyte remains essentially an absorptive cell.

\section{CONCLUSION}

In conclusion, polyunsaturated long-chain fatty acid absorption does not appear to be very dissimilar to that of long-chain fatty acid absorption, particularly mono- unsaturated long-chain fatty acid absorption. Indeed, it has been accepted that saturated long-chain fatty acids are poorly absorbed (Bloom et al, 1951; Bernard et al, 1987). However, polyunsaturated longchain fatty acid absorption processes require further investigation to elucidate some particularities of the lumenal phase with reference to the polarity of polyunsaturated fatty acids and some specific absorption processes of the mucosal phase, in particular esterification modalities. Better information on the emulsification, hydrolysis and micellarization of polyunsaturated long-chain fatty acids is essential for the adaptation of possible dietary supplements. Furthermore, a better understanding of the role of the enterocyte fatty acid binding proteins towards polyunsaturated fatty acids might bring to light the esterification step crucial for the fate of the polyunsaturated fatty acids in the organism. Indeed, the energetic or regulator further utilization of these essential fatty acids might depend on their integration into phospholipids or triglycerides as soon as they are absorbed.

\section{ACKNOWLEDGMENTS}

The authors thank MF Girardier and MC Monnot for their skillful technical assistance.

\section{REFERENCES}

Bass NM (1985) Function and regulation of hepatic and intestinal fatty acid binding proteins. Chem Phys Lipids 38, 95-114

Bang HO, Dyerberg J, Hjorne N (1976) The composition of food consumed by Greenland Eskimos. Acta Med Scand 200, 59-73

Bernard A, Carlier H, Caselli C (1979a) Étude au microscope électronique de la sécrétion des chylomicrons chez le rat par l'entérocyte 
dans la lumière des capillaires lymphatiques. CR Acad Sci Paris 289, 1171-1174

Bernard A, Caselli C, Carlier H, Bezard J (1979b) Electron microscopic investigation of the intestinal epithelial cells and the lipoprotein particles of lymph in rats after ingestion of peanut, canbra or rapeseed oil in the diet. $J$ Physiol (Paris) 75, 559-570

Bernard A, Echinard B, Carlier H (1987) Differential intestinal absorption of two fatty acid insomers elaidic and oleic acids. Am J Physiol 253 (Gastrointest Liver Physiol 16) G751G759

Bernard A, Carlier H (1989) Absorption and metabolism of lipids. In: Intestinal Metabolism of Xenobiotics (Koster AS, Richter E, Lauterbach F, Hartmann F, eds) Progr Pharmacol Clin Pharmacol, Gustav Fischer, Stuttgart, 217-230

Bernard A, Carlier H (1991) Absorption and intestinal catabolism of fatty acids in the rat: effect of chain length and unsaturation. Exp Physiol 76, 445-455

Bernard A, Carlier H (1991) Esterification des acides gras insaturés au cours de l'absorption : étude en culture organotypique d'intestin de souris en fonction de l'âge. Reprod Nut Dev vol 31, No 3

Bernard A, Caselli C, Carlier H (1991) Linoleic acid and chyloportal partition and metabolism during its intestinal absorption. Ann Nutr Metab (in press)

Bisgaier Cl, Glickman RM (1983) Intestinal synthesis, secretion, and transport of lipoproteins. Ann Rev Physiol 45, 625-636

Blomstrand R (1955) Transport form of decanoic acid $1{ }^{14} \mathrm{C}$ in the lymph during intestinal absorption in the rat. Acta Physiol Scand 34, 67-704

Bloom B, Chaikoff IL, Reinhardt WO (1951) Intestinal lymph as pathway for transport of absorbed fatty acids of different chain lengths. Am J Physiol 166, 451-455

Borgström B (1955) Transport form of ${ }^{14} \mathrm{C}$ decanoic acid in portal and inferior vena cava blood during absorption in the rat. Acta Physiol Scand 34, 71-74

Borgström B (1977) The action of bile salts and other detergents on pancreatic lipase and the interaction with colipase. Biochim Biophys Acta 488, 381-391
Bottino NR, Vandenberg GA, Reiser R (1967) Resistance of certain long-chain polyunsaturated fatty acids of marine oils to pancreatic lipase hydrolysis. Lipids 2, 489-493

Bourre JM, Dumont O, Piciotti M, Pascal G, Durand $G$ (1989) Polyunsaturated fatty acids of the $\mathrm{n}-3$ series and nervous system development. In: Dietary $\omega-3$ and $\omega-6$ Fatty Acids (Galli C, Simopoulos AP, eds) NATO ASI Series, Plenum Press, NY, vol 171, 159-175

Brenner RR (1981) Nutritional and hormonal factors influencing desaturation of essential fatty acids. Prog Lipid Res 20, 41-47

Brindley DN (1974) The intracellular phase of fat absorption. In: Biomenbranes (Smyth DH, ed) Plenum Press, London, vol 4B, 621-672

Brockerhoff H, Yurkowski M (1966) Stereospecific analyses of several vegetable fats. J Lipid Res 7, 62-64

Brockerhoff H, Hoyle RJ, Huang PC (1966a) Positional distribution of fatty acids in the fats of a polar bear and a seal. Can J Biochem 44, 1519-1525

Brockerhoff H, Hoyle RJ, Wolmark N (1966b) Positional distribution of fatty acids in triglycerides of animal depot fats. Biochim Biophys Acta 125, 55-59

Brockerhoff H, Hoyle RJ, Huang PC, Litchfield C (1968) Positional distribution of fatty acids in depot triglycerides of aquatic animals. Lipids 3, 24-29

Bugaut M, Carlier H (1987) Role of intestinal hydrolases, endogenous subtrates and chyloportal partition in fat absorption. In: Fat $A b$ sorption (Kuksis A, ed) CRC Press Inc, Boca Raton, FL, vol 1, 197-231

Cardell RR Jr, Badenhausen S, Porter KR (1967) Intestinal triglyceride absorption in the rat. An electron microscopical study. $J$ Cell Biol 34, 123-155

Carlier H (1971) Absorption en fonction du temps par un segment d'intestin de rat "in situ" de monopalmitine, d'acide palmitique et d'acide oléique tritié. J Microsc 12, 193-204

Carlier H, Bezard J (1975) Electron microscopic radioautographic study of intestinal absorption of decanoic and octanoic acids in the rat. $J$ Cell Biol 65, 383-397

Caselli C, Carlier H, Bezard J (1979) Size of lipoprotein particles in the intestinal lymph of 
rats fed on corn oil, peanut oil, rapeseed oil or canbra oil. Nutr Metab 23, 73-87

Chapus C, Sari H, Semeriva M, Desnuelle P (1975) Role of colipase in the interfacial absorption of pancreatic lipase at hydrophobic interfaces. FEBS Lett 58, 155-158

Chen IS, Subramaniam S, Cassidy MM, Sheppard AJ, Vahouny GV (1985) Intestinal absorption and lipoprotein transport of ( $\omega-3)$ eicosapentaneonic acid. J Nutr 115, 219-225

Chen IS, Le T, Subramaniam S, Cassidy MM, Sheppard AJ, Vahouny GV (1987a) Comparison of the clearances of serum chylomicron triglycerides enriched with eicosapentaenoic acid or oleic acid. Lipids 22, 318-321

Chen IS, Hotta SS, Ikeda I, Cassidy MM, Sheppard AJ, Vahouny GV (1987b) Digestion, absorption and effects on cholesterol absorption of menhaden oil, fish oil concentrate and corn oil by rats. $J$ Nutr $117,1676-1680$

Chernenko GA, Barrowman JA, Kean KT, Herzberg GR, Keough KMW (1989) Intestinal absorption and lymphatic transport of fish oil (max EPA) in the rat. Biochim Biophys Acta 1004, 95-102

Chow SL, Hollander D (1978a) Arachidonic acid intestinal absorption: mechanism of transport and influence of luminal factors on absorption in vitro. Lipids 13, 768-776

Chow SL, Hollander D (1978b) Linoleic acid absorption in the unanesthetized rat: mechanism of transport and influence of luminal factors on absorption. Lipids 14, 378-385

Christiansen EN, Rostveit T, Norum KR, Thomassen MS (1986) Fatty acid chain elongation in rat small intestine. Biochem $J 273$, 293-295

Clark B, Hubscher G (1960) Biosynthesis of glycerides in the mucosa of small intestine. Nature 185, 35-37

Clement G, Clement J, Courel E, Klepping J, Briet $S$ (1963) Absorption des acides gras à chaines moyennes et courtes. In: Biochemical Problems of Lipids (Frazer AC, ed) Elsevier, Scientific Publishing Company, Amsterdam, vol 1, 172-179

DeNigris SJ, Hamosh M, Kasbekar DK, Lee TC, Hamosh $P$ (1988) Lingual and gastric lipases: species differences in the origin of prepancreatic digestive lipases and in the localization of gastric lipase. Biochim Biophys Acta 959, 38-45
Dietschy JM (1978) General principles governing movement of lipids across biological membranes. In: Disturbances in Lipid and Lipoprotein Metabolism (Dietschy JM, Gotto AM Jr, Ontko JA, eds) Am Physiol Soc Bethesda, $M D$ 1-28

Dyerberg J, Bang HO, Hjorne N (1975) Fatty acid compositon of the plasma lipids in Greenland Eskimos. Am J Clin Nutr 28, 958966

Dyerberg J, Bang HO, Stofferson E, Moncada S, Vane JR (1978) Eicosapentaenoic acid and prevention of thrombosis and atherosclerosis. Lancet i, 117-119

El Boustani S, Colette C, Monnier L, Descomps B, Crastes de Paulet A, Mendy F (1987) Enteral absorption in man of eicosapentaenoic acid in different chemical forms. Lipids 22 , $711-714$

Fischer S, Weber PC (1983) Thromboxane $A_{3}$ $\left(\mathrm{TXA}_{3}\right)$ is formed in human platelets after dietary eicosapentaenoic acid (C20:5 w3). Biochem Biophys Res Commun 116, 1091-1099

Friedman HI, Nylund B (1980) Intestinal fat digestion, absorption and transport. Am J Clin Nutr 33, 1108-1139

Galloway JH, Cartwright IJ, Woodcock BE, Greaves M, Russel RGG, Preston FE (1985) Effects of dietary fish oil supplementation on the fatty acid composition of the human platelet membrane: demonstration of selectivity in the incorporation of eicosapentaenoic acid into membrane phospholipid pools. Clin Sci $68,449-454$

Gangl A, Ockner RK (1975) Intestinal metabolism of plasma free fatty acids. Intracellular compartmentation and mechanisms of control. J Clin Invest 55, 803-813

Garg ML, Keelan M, Thomson ABR, Clandinin MT (1988) Fatty acid desaturation in the intestinal mucosa. Biochim Biophys Acta 958, 139-141

Goodnight SH, Harris WS, Connor WE, Illingworth DR (1982) Polyunsaturated fatty acids, hyperlipidemia and thrombosis. Atheriosclerosis 2, 87-113

Greenberger NJ, Franks JJ, Isselbacher $\mathrm{KJ}$ (1965) Metabolism of $1-14 \mathrm{C}$ octanoic and 1 ${ }^{14} \mathrm{C}$ palmitic acids by rat intestinal slices. Proc Soc Exp Biol Med 120, 468-472

Greenberger NJ, Rodgers JB, Isselbacher KJ (1966) Absorption of medium and long chain 
triglycerides. Factors influencing their hydrolysis and transport. J Clin Invest 45, 217-227

Hamazaki T, Hirai A, Terano T, Sajiki J, Kondo S, Fujita T, Tamura Y, Kumagai A (1982) Effects of orally administered ethyl ester of eicosapentaenoic acid (EPA C20:5 n-3) on PGI-like substance production by rat aorta. Prostaglandins 23, 557-567

Hamazaki T, Urakaze $M$, Makuta $M$, Ozawa $A$, Soda $Y$, Tatsumi $H$, Yano S, Kumagai A (1987) Intake of different eicosapentaenoic acid containing lipids and fatty acid pattern of plasma lipids in the rat. Lipids 22, 994-998

Harris WS, Connor WE (1980) The effects of salmon oil upon plasma lipids, lipoproteins, and triglyceride clearance. Trans Assoc Am Physicians 43, 148-155

Harris WS, Williams GG (1989) Emulsification enhances the absorption of fish oil in man. In: Health Effects of Fish and Fish Oils (Chandra RK, ed) ARTS Biomedical Publishers and Distributors, St John's, Newfoundland, 211-218

Hofmann AF (1976) Fat digestion: the interaction of lipid digestion products with micellar bile acid solutions. In: Lipid Absorption: Biochemical and Clinical Aspects (Rommel K, Goebell H, Bohmer R, eds) MTP Press Ltd, Lancaster, UK, 3-18

Holman RJ (1964) Nutritional and metabolic interelationships between fatty acids. Fed Proc 23, 1062-1067

Hyun SA, Vahouny GV, Treadwell CR (1967) Portal absorption of fatty acids in lymph and portal vein cannulated rats. Biochim Biophys Acta 137, 296-305

Johnston JA (1976) Triglyceride biosynthesis in the intestinal mucosa. In: lipid Absorption: Biochemical and Clinical Aspects (Rommel K, Goebell H, Bohmer R, eds) MTP Press Ltd, Lancaster, UK, 85-94

Kern F Jr, Borgström B (1965) Quantitative study of the pathways of triglyceride synthesis by hamster intestinal mucosa. Biochim Biophys Acta 98, 520-531

Kromann N, Green A (1980) Epidemiological studies in the Upernavik district, Greenland: incidence of some chronic diseases. Acta Med Scand 208, 401-406

Lassere M, Mendy F, Spielman D, Jacotot B (1985) Effects of different dietary intakes of essential fatty acids on C20:3 $\omega 6$ and C20:4 $\omega 6$ serum levels in human adults. Lipids 20 , 4, 227-233

Lawson LD, Hughes BG (1988a) Human absorption of fish oil fatty acids as triacylglycerols, free acids, or ethyl esters. Biochem Biophys Res Commun 152, 328-335

Lawson LD, Hughes BG (1988b) Absorption of eicosapentaenoic acid and docosahexaenoic acid from fish oil triacyglycerols or fish oil ethyl esters co-ingested with a high-fat meal. Biochem Biophys Res Commun 156, 960963

Lawson LD, Hughes BG (1988c) Triacylglycerol structure of plant and fungal oils containing $\gamma$ - linolenic acid. Lipids 23, 313-317

Liu CCF, Carlson SE, Rhodes PG, Rao VS, Meydreck EF (1987) Increase in plasma phospholipid docosahexaenoic and eicosapentaenoic acids as a reflection of their intake and mode of administration. Pediatr Res 22, 292-296

Lowe JB, Sacchettini JC, Laposata M, McQuilIan JJ, Gordon JI (1987) Expression of rat intestinal fatty acid binding protein in Escherichia coli. J Biol Chem 262, 5931-5937

McDonald GB, Saunders DR, Weidman M, Fischer $L$ (1980) Portal veinous transport of long chain fatty acids absorbed from rat intestine. Am J Physiol 239, G141-G150

McDonald GB, Weidman M (1987) Partitioning of polar fatty acids into lymph and portal vein after intestinal absorption in the rat. Quart $J$ Exp Physiol 72, 153-159

Moreau $H$, Gargouri $Y$, Bernadal A, Pieroni G, Verger R (1988) Étude biochimique et physiologique des lipases préduodénales d'origines animale et humaine. Rev Fr Corps Gras 4, 169-176

Nelson GJ, Ackman RG (1988) Absorption and transport of fat in mammals with emphasis on n-3 polyunsaturated fatty acids. Lipids 23 , 1005-1014

Nilsson A, Landin B, Jensen E, Akesson B (1987) Absorption and lymphatic transport of exogenous and endogenous arachidonic and linoleic acid in the rat. Am J Physiol 252 (Gastrointest Liver Physiol 15) G817-G824

Ockner RK, Manning JA (1976) Fatty acid binding protein: role in esterification of absorbed 
long chain fatty acid in rat intestine. $J$ Clin Invest 58, 632-641

Pavero C, Grappin S, Caselli C, Bernard A, Carlier $H$ (1989) Lymphatic transport of arachidonic and eicosapentaenoic acids in the rat. Ist Congress Eurolipid ETIG Paris, vol II, 821-828

Pavero C, Caselli C, Bernard A, Carlier H (1991) Absorption and metabolism of erucic acid in the rat. Rev Fr Corps Gras 9/10, 301-307

Philbrick DJ, Mahadevappa VG, Ackman RG, Holub BJ (1987) Ingestion of fish oil or a derived $n-3$ fatty acid concentrate containing eicosapentaenoic acid (EPA) affects fatty acid composition of individual phospholipids of rat brain, sciatic nerve and retina. J Nutr 117 , 1663-1670

Rayo JM, Cour O, Caselli C, Bernard A, Carlier $H$ (1991) Absorption intestinale chez le rat d'huile de foie de morue, d'huile de menhaden, d'ethyl esters d'acides docosahexaénoique et éicosapentaénoique et d'huile de maïs. Reprod Nutr Dev vol 31, $n^{\circ} 3$ (in press)

Reicks M, Hoadley J, Subramaniam S, Morehouse KM (1990) Recovery of fish oil-derived fatty acids in lymph of thoracic ductcannulated Wistar rats. Lipids 25, 6-10

Roy $C C$, Roulet $M$, Lefebvre $D$, Chartrand $L$, Lepage G, Fournier LA (1979) The role of gastric lipolysis on fat absorption and bile acid metabolism in the rat. Lipids 14,811 815

Sabesin SM (1976) Ultrastructural aspects of the intracellular assembly, transport and exocytosis of chylomicrons by rat intestinal absorptive cells. In: Lipid Absorption: Biochemical and Clinical Aspects (Rommel K, Goebell H, Bohmer R, eds) MTP Press Ltd, Lancaster UK, 113-145

Samuelsson B (1983) Leukotrienes: mediators of immediate hypersensitivity reactions and inflammation. Science 220, 568-575

Shiau YF (1990) Mechanism of intestinal fatty acid uptake in the rat: the role of an acidic microclimate. J Physiol 421, 463-474

Shiau YF, Fernandez $P$, Jackson MJ, MacMonagle $S$ (1985) Mechanisms maintaining a low . microclimate in the intestine. Am J Physiol 248, G608-G617

Simopoulos AT (1989) General recommendations on dietary fats for human consumption.
In: Dietary $\omega-3$ and $\omega-6$ Fatty Acids (Galli C, Simopoulos AP, eds) NATO ASI Series, Plenum Press, NY, vol 171, 403-404

Stremmel W (1988) Uptake of fatty acids by jejunal mucosal cells is mediated by a fatty acid binding membrane protein. $J$ Clin lnvest 82 , 2001-2010

Stremmel W, Lotz G, Strohmeyer G, Berk PD (1985) Identification, isolation and partial characterization of a fatty acid binding protein from rat jejunal microvillous membranes. $J$ Clin Invest 75, 1068-1076

Terano T, Hirai A, Hamazaki A, Kobayashi S, Fujita T, Tamura Y, Kumagai A (1983) Effect of oral administration of highly purified eicosapentaenoic acid on platelet function, blood viscosity and red cell deformability in healthy human subjects. Atherosclerosis 46, 321-331

Thomassen MS, Helgerud P, Norum KR (1985) Chain-shortening of erucic acid and microperoxisomal $\beta$-oxidation in rat small intestine. Biochem J 255, 301-306

Thomson ABR (1978) Intestinal absorption of lipids: influence of the unstirred water layer and bile micelle. In: Disturbances in Lipid and Lipoprotein Metabolism (Dietschy JM, Gotto AM Jr, Ontko JA, eds) Am Physiol Soc (Bethesda, MD) 29-56

Thomson ABR, Dietschy JM (1981) Intestinal lipid absorption: major extracellular and intracellular events. In: Physiology of Intestinal Tract (Johnson LR, ed) Raven Press, NY, 1147-1220

Thomson ABR, Keelan M, Garg ML, Clandinin MT (1989) Intestinal aspects of lipid absorption: in review. Can J Physiol Pharmacol 67, 179-191

Tso P, Simmonds WG (1984) The absorption of lipid and lipoprotein synthesis. In: Lipid Research Methodology (Story JA, ed) Alan R Liss Inc, NY, 191-216

Vahouny GV (1985) Inhibition of cholesterol absorption by natural products. In: Drugs Affecting Lipio Metabolism VIII (Kritchevsky D, Holmes WL, Paoletti R, eds) Plenum, Press, NY, 265-279

Vallot A, Bernard A, Carlier H (1985) Influence of the diet on the portal and lymph transport of decanoic acid in rats. Simultaneous study of its mucosal catabolism. Comp Biochem Physiol 82A, 693-699 
Yang LY, Kuksis A, Myher JJ (1989) Lumenal hydrolysis of menhaden and rapeseed oils and their fatty acid methyl and ethyl esters in the rat. Biochem Cell Biol 67, 192-204

Wilson FA, Sallee VL, Dietschy JM (1971) Unstirred water layers in intestine: rate determi- nant of fatty acid from micellar solutions. Science 174, 1031-1033

Yurkowski M, Brockerhoff $H$ (1966) Fatty acid distribution of triglycerides determined by deacylation with methyl magnesium bromide. Biochim Biophys Acta 125, 55-59 